\title{
Genistein inhibits Brca1 mutant tumor growth through activation of DNA damage checkpoints, cell cycle arrest, and mitotic catastrophe
}

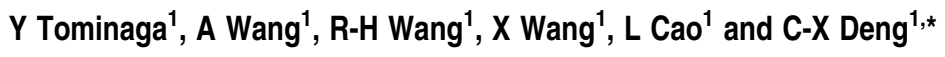

Epidemiological studies revealed that amount of consumption of soy was inversely related to incidence of breast cancer. Genistein, the predominant isoflavone in soy, has been reported to reduce the incidence of breast cancer in animal models. To investigate whether genistein has a therapeutic effect on BRCA1-associated breast cancer, we treated Brca1 mutant mammary tumor cells with genistein. We showed that genistein treatment depleted the G1 population of cells, which was accompanied by an accumulation of cells at G2. Some genistein-treated cells entered mitosis; however, they exhibited chromosome abnormalities and maintained tetraploidy owing to abortive mitotic exit. A fraction of G2 cells underwent endoreduplication and became polyploid, which was accompanied by increased cell death through activating DNA damage response. Furthermore, our data indicated that Brca1 mutant cells were more sensitive to genistein than some other types of cancer cells, highlighting a good therapeutic potential of genistein for BRCA1-associated breast cancer.

Cell Death and Differentiation (2007) 14, 472-479. doi:10.1038/sj.cdd.4402037; published online 6 October 2006

Breast cancer is one of the most common cancers and affects approximately one in eight women in Western countries. In the USA, approximately 210000 new cases of breast cancer are diagnosed each year and about 40000 patients die. About $90 \%$ of breast cancers occur sporadically, with the remaining being due to inheritable familiar cancer syndromes. ${ }^{1-4}$ The breast cancer-associated gene 1 (BRCA1) is the most frequently mutated tumor suppressor gene found in familial breast cancers. ${ }^{5}$ It is estimated that BRCA1 mutation carriers have a $50-80 \%$ risk of developing breast cancer by age 70 years. ${ }^{6-8}$ Because of their high risk for cancer, BRCA1-mutation carriers often worry about developing breast cancer and are in special need of a preventative and therapeutic agents. In Eastern countries like China and Japan, the risk for breast cancer is much lower than in Western countries. ${ }^{9}$ Various studies have shown that this reduced risk may be associated with a high amount of soy consumption in these countries. ${ }^{10,11}$

The active inhibitory components of soy are thought to be isoflavone phytoestrogens, such as genistein and daidzein. ${ }^{12}$ Genistein has been shown to inhibit cell growth by inducing cell cycle arrest, possibly through upregulation of cell cycle-dependent kinase (Cdk) inhibitor p21, cyclin B1, and phospho-p34. ${ }^{13,14}$ Genistein can also inhibit decatenation of DNA by inhibiting topoisomerase II activity and induce DNA damage by generating DNA double-strand breaks (DSBs) through stabilizing the covalent topisomerase II-DNA cleavage complex. ${ }^{15}$ Furthermore, genistein has been shown to induce apoptosis through decreased expression of $\mathrm{Bcl} 2$ and upregulation of Bax. ${ }^{16}$
Animal studies have shown that genistein treatment inhibits chemically induced mammary cancer formation (reviewed in Magee and Rowland ${ }^{17}$ ). It was postulated that genistein exerts its chemopreventive effect by enhancing mammary cell maturation and lobular-alveolar development, thus reducing cell proliferation in the mammary gland. ${ }^{18}$ Although most epidemiological and laboratory studies have demonstrated a protective role of genistein against breast cancer, some concerns still remain. It was shown that genistein could enhance MCF7 cell proliferation in vitro and tumor growth of implanted MCF7 cells in ovariectomized nude mice. ${ }^{19,20}$ It turns out that genistein has a biphasic effect on cell growth: low concentrations of genistein (i.e. $<10 \mu \mathrm{M}$ ) stimulate cell proliferation, whereas higher concentrations inhibit cell proliferation. ${ }^{19}$ Thus, both the dose and timing of exposure are critical factors in determining the effects of genistein on breast cancer risk.

Currently, there has been no report about the effects of genistein on BRCA1-associated breast cancer, which is a major form of familial breast cancer syndrome. ${ }^{6-8}$ Given the observation that genistein inhibits most different types of cancers studied so far, we hypothesize that genistein may inhibit the growth of BRCA1-associated breast cancer. To investigate this, we treated mammary tumor cells derived from Brca1 mutant mice with genistein. Our data indicated that genistein inhibits the growth of tumor cells both in vitro and in allograft nude mice by inducing G2 arrest, polyploid cell formation, mitotic catastrophe, and apoptosis characterized by annexin-V staining and accumulation of subG1 population

\footnotetext{
${ }^{1}$ Genetics of Development and Diseases Branch, National Institute of Diabetes and Digestive and Kidney Diseases, National Institutes of Health, Bethesda, MD, USA *Corresponding author: Dr C-X Deng, Genetics of Development and Diseases Branch, National Institute of Diabetes and Digestive and Kidney Diseases, National Institutes of Health, 10/9N105, 10 Center Drive, Bethesda, MD 20892, USA. Tel: + 301402 7225; Fax: +301480 1135

E-mail: chuxiad@bdg10.niddk.nih.gov

Keywords: genistein; BRCA1; DNA damage; cell cycle; chemoprevention

Abbreviations: BRCA1, breast cancer-associated gene-1; Cdk, cell cycle-dependent kinase; DSBs, double-strand breaks; $\gamma \mathrm{H} 2 \mathrm{AX}$, phosphorylated form of H2AX; MTT assay, 3-(4,5-dimethylthiazol-2-yl)-2,5-diphenyl tetrazolium bromide assay; PI, propidium iodide

Received 13.2.06; revised 18.7.06; accepted 31.7.06; Edited by M Blagosklonny; published online 6.10.06
} 
of cells. We also provide evidence that genistein treatment activates DNA damage response, which inhibits growth and eliminates Brca1 mutant cancer cells.

\section{Results}

Effects of genistein on the growth of mammary tumor cells. Four tumor cell lines derived from mammary tumors of Brca1 ${ }^{\mathrm{Ko} / \mathrm{Co}} \mathrm{Wap}-\mathrm{Cre} ; \mathrm{p53}^{+/-}$mice (W525 and W780), MMTV-Neu (Neu), and MMTV-Ras (Ras) ${ }^{21}$ were used in this experiment. We plated $10^{4}$ cells into each well of a 24-well plate with varying concentrations of genistein, ranging from $0,1,2.5,5,7.5,10,20,40$ and $80 \mu \mathrm{M}$ added $24 \mathrm{~h}$ later. The cultures were stopped 3 days later and were subjected to 3-(4,5-dimethylthiazol-2-yl)-2,5-diphenyl tetrazolium bromide (MTT) assay. Our data revealed a similar dose-dependent reduction of cell quantity starting from $5 \mu \mathrm{M}$, with a survival fraction of $50 \%\left(\mathrm{SF}_{50}\right)$ in these cells at doses between 15 and $20 \mu \mathrm{M}$ of genistein (Figure 1a). Next, we treated these cells with $15 \mu \mathrm{M}$ of genistein for a prolonged period of time up to 7 days. The data indicated that both BRCA1 mutant cell lines were significantly more sensitive than the other two cell lines 5 days after the treatment (Figure 1b). All W780 cells died 7 days after the treatment, whereas 20,30 and $45 \%$ of W525, Ras and Neu cells were still alive (Figure 1b).

This observation indicates that Brca1 mutant cells are more sensitive to genistein treatment than some other types of cancer cells during a prolonged period of time. To investigate
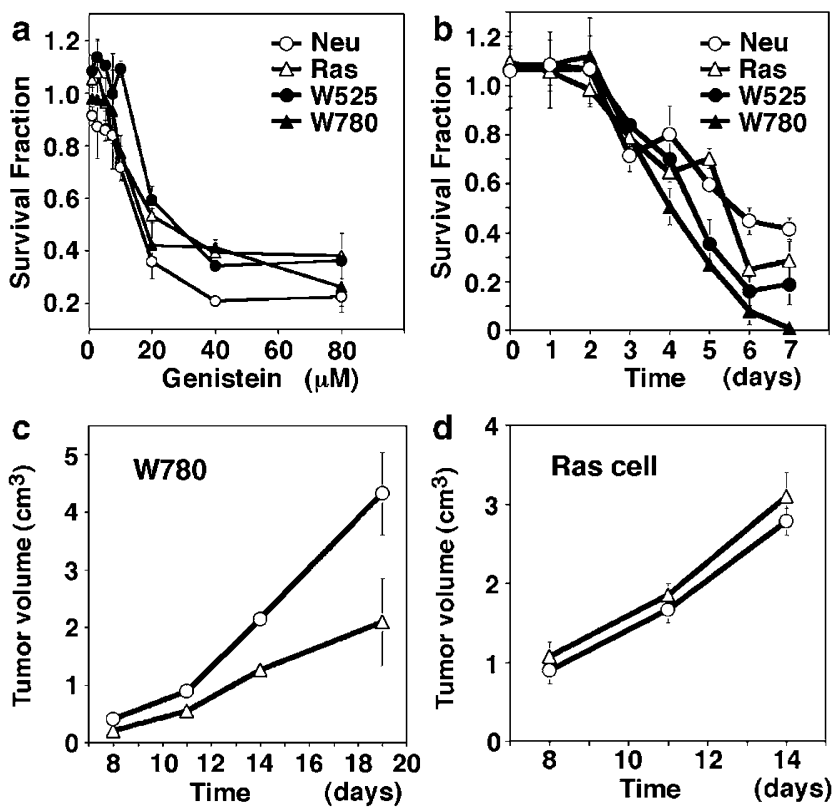

Figure 1 Genistein inhibited growth of mammary cancer cells. (a-c) Cell growth measured by MTT assay. (a) Continuous genistein exposure to Neu and Ras cells (Brca1 wild type) and W525 and W780 cells (Brca1 mutant) at different concentrations for 3 days. No statistic differences were detected in all the concentrations examined ( $t$-test $P=0.883$ ). (b) Long-term exposure (7 days) at $15 \mu \mathrm{M}$ genistein $\left(\mathrm{SF}_{50}\right)$ to four tumor cells. A significant difference between Brca1 Wt versus Brca1 Wt was observed after extended treatment $(P=0.002)$. (c, d) Allograft assay of W780 (c) and Ras (d). Circle: AIN-76A (control diet); triangle: AIN76 A with $750 \mathrm{ppm}(0.75 \mathrm{mg} / \mathrm{g})$ genistein. Bars showed SE on both sides. $P=0.001$ for panel (c) and $P=0.408$ for panel (d) measured at day 14 whether the distinct response of Brca1 mutant cells and some other types of cancers to genistein also occurs in vivo, we performed allograft experiments by inoculating these cells into female nude mice. At 8 days after inoculation of $1 \times 10^{6}$ cells subcutaneously on the lateral body wall of recipient mice, small tumor nodules became visible. We started to measure tumor size every 3 days up to day 19 when tumors in control mice were too large (about $1.5 \mathrm{~cm}$ in diameter) to continue the study. Our data indicated that Brca1 tumors developed from genistein-treated mice were about $1 / 3$ in volume compared with those developed from control mice (Figure 1c), whereas no obvious differences were observed between genisteintreated and vehicle-treated Ras cells (Figure 1d). These observations indicated that genistein suppresses the growth of Brca1 mutant tumor efficiently both in vitro and in vivo; however, its inhibition on some other types of breast cancer cells is not obvious.

Genistein treatment results in polyploidy and cell death. To explore the mechanism of the growth defects observed in Brca1 mutant cells, we first performed flow cytometry of propidium iodide $(\mathrm{PI})$-stained cells after they were treated with genistein for 3 days. Our data revealed a dosage-dependent increase of subG1 population that was accompanied by reduced G1 and increased polyploid ( $4 n$ and $8 n$ ) cells (Figure 2a). Next, we stained the cells with annexin- $\mathrm{V}$, which is an early-phase marker of apoptotic cell death. Our data revealed a moderate increase of annexin$\mathrm{V}$-positive cells at 48 and $72 \mathrm{~h}$ after genistein exposure (Figure 2b).

In order to follow cell cycle progression of genistein-treated cells, we pulse-labeled cells with BrdU before they were harvested at different time points. We found that $6 \mathrm{~h}$ after genistein treatment, the fraction of G1 population was significantly decreased compared with untreated control (from 17 to $8 \%$, Figure 2c). The G1 population was further decreased during the prolonged treatment, and reached about $2 \%$ at $72 \mathrm{~h}$. These data suggest that genistein treatment prevents cells from returning to the $\mathrm{G} 1$ phase. The fraction of cells in the $S$ phase was unchanged in the first $6 \mathrm{~h}$ after genistein treatment, decreased slightly at $24 \mathrm{~h}$, and dramatically decreased thereafter. The reduced population of Sphase cells corresponded well with the reduced population of G1 cells. The fraction of cells in the G2/M phase significantly increased at 24 and $48 \mathrm{~h}$ and then dropped to the control level at $72 \mathrm{~h}$ after genistein treatment. The fraction of the $8 n$ population started to increase 6-24h after the treatment and became significantly higher at 48 and $72 \mathrm{~h}(41 \%$ at both time points). There was a significant increase of the polyploid $S$ population of cells in the first $6 \mathrm{~h}$ after treatment. However, this population of cells reduced to the control level at $24 \mathrm{~h}$ and then further reduced thereafter (Figure $2 \mathrm{c}$ ). These results indicated that cells of $4 n$ did not return to $\mathrm{G} 1$ through mitosis; instead they started the second round of the $S$ phase leading to the accumulation of polyploid cells. These cells may gradually die, as reflected by the increased subG1 population (Figure 2c).

Although both Brca1 tumor cell lines exhibited similar cell cycle profiles, and a nearly complete depletion of G1 population upon genistein treatment (Supplementary Figures $1 \mathrm{a}, \mathrm{b}), 19 \%$ of Ras held at $\mathrm{G} 1$ after $48 \mathrm{~h}$ exposure, and $\mathrm{Neu}$ 


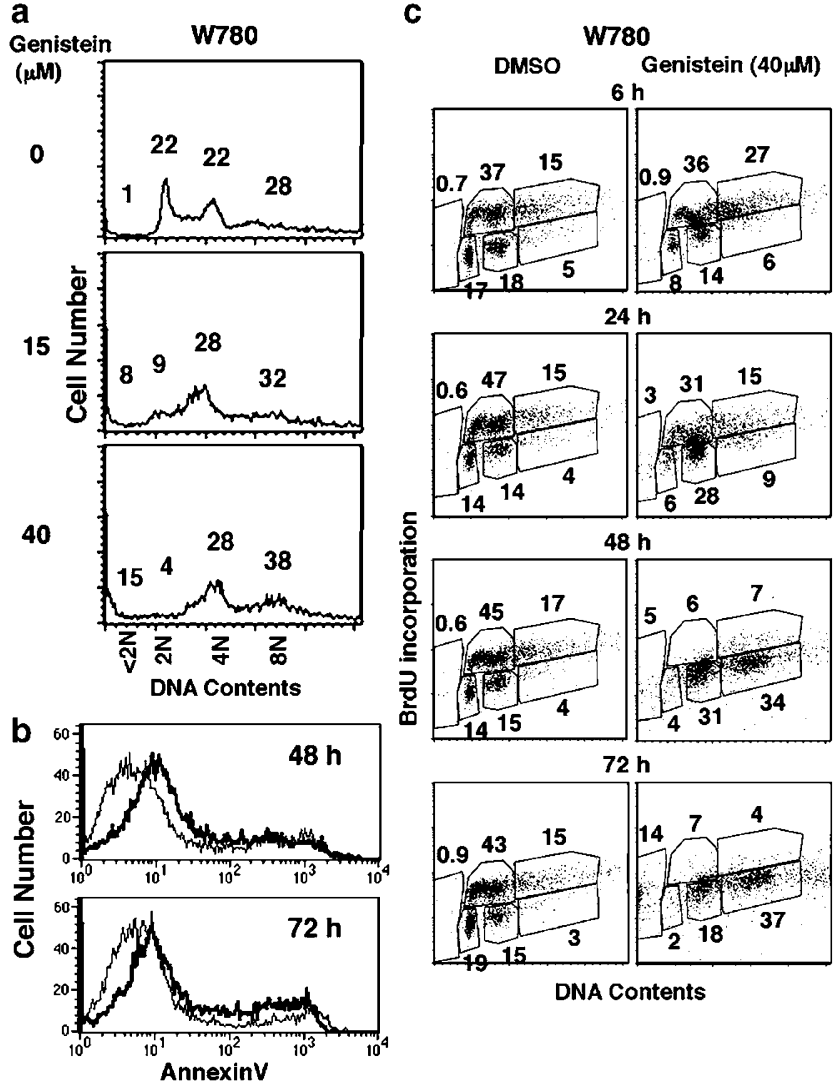

Figure 2 Genistein treatment induces cell death, reduced proliferation, and polyploid formation. (a) Flow cytometry analysis of cells with propidium iodide (PI) staining at 15 or $40 \mu \mathrm{M}$ genistein treatment for 3 days. Numbers in the histogram show fractions (percent) of subG1, $2 n, 4 n$, and polyploidy from left to right. (b) Flow cytometry analysis for living cells with anti-annexinV-FITC fluorescent immunostaining. Thin and thick lines show DMSO- and $40 \mu \mathrm{M}$ genistein-treated W780 cells, respectively. (c) Flow cytometry analysis with $\mathrm{PI}$ and anti-BrdU antibody conjugated with FITC fluorescent immunostaining. BrdU was pulse-labeled for $30 \mathrm{~min}$ prior to the harvesting of the cells

cells showed an intermediate phenotype (Supplementary Figures $1 \mathrm{c}, \mathrm{d}$ ). These data indicate that different types of cancer cells do not always have a similar response to genistein treatment.

Genistein exposure causes abnormalities in the mitosis. Because the above analysis does not reflect cells in mitotic phase, we measured the mitotic fraction by using an antibody to phosphorylated histone $\mathrm{H} 3$ as a mitotic marker after continuous treatment of genistein. We found that the mitotic fraction of genistein-treated cells was significantly lower than control cells at most time points measured (Figures $3 a$ and b).

To monitor progression of mitosis, we stably transfected W780 cells with a histone H2B-GFP-expressing vector and observed these cells using a fluorescent microscope. We found that genistein-treated cells could enter the prophase and the metaphase (data now shown); however, the majority (91.4\%) of anaphases exhibited abnormal chromosomal structures characterized by chromosomal bridges and/or lagging chromosome (Figures $3 \mathrm{c}, \mathrm{d}$ ). In contrast, the abnormal
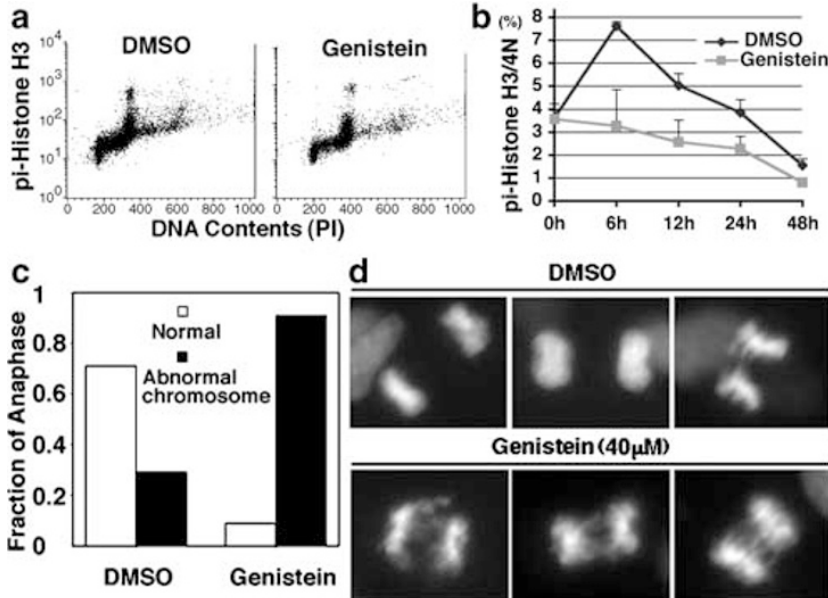

d

DMSO
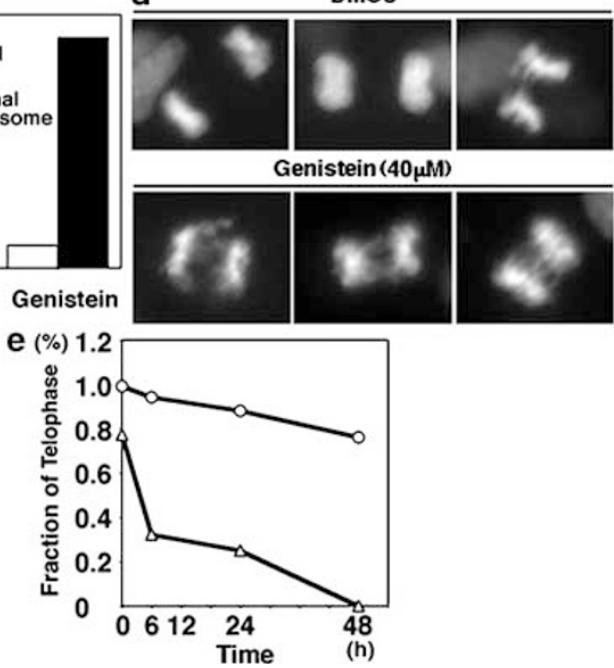

Figure 3 Abnormal cell cycle progression and chromosomal segregation after exposure of genistein. (a) Flow cytometry analysis of W780 cells stained with PI and phosphorylated histone $\mathrm{H} 3$ (Ser10) $6 \mathrm{~h}$ after exposure to DMSO or genistein. (b) Mitotic fractions at 6,12, 24, and $48 \mathrm{~h}$ after genistein exposure. Means from three independent experiments were presented in the graph. There are significant differences between DMSO- or genistein-treated cells: $6 \mathrm{~h}: P=0.009 ; 12 \mathrm{~h}$ : $P=0.002 ; 24 \mathrm{~h}: P=0.004 ; 48 \mathrm{~h}: P=0.031$. Circle and triangle show DMSO- and $40 \mu \mathrm{M}$ genistein-treated W780 cells. (c) Fractions of cells in the anaphase. W780 cells were stably transfected by a histone H2B-GFP expression vector so that their DNA can be visualized. (d) Representative images of (c) under a fluorescent microscope. The left two images at the upper side were categorized as normal. The other four images were categorized as abnormal. Cells were treated with DMSO or genistein for $8 \mathrm{~h}$. (e) Fraction of W780 cells in the telophase after treatment with genistein (triangle) and DMSO (circle) at different times. Over 3000 cells for DMSOor genistein-treated cells at each point were counted

anaphase was $29.2 \%$ in untreated cells (Figure 3c). This frequency of spontaneous abnormal anaphase was comparable with that found in Brca1 mutant MEF cells reported previously due to the impaired spindle checkpoint defect in these cells. ${ }^{22}$ In addition, the extent of chromosome abnormality in genistein-treated cells was much more severe than that of untreated cells. Of note, genistein treatment significantly reduced the frequency of cells in the telophase $6 \mathrm{~h}$ after treatment, and by $48 \mathrm{~h}$ after treatment there were hardly any telophase cells in the genistein-treated population (Figure 3e). This observation suggests that genistein treatment prevents cells from finishing mitosis.

To determine the time point when genistein-treated cells were blocked during mitosis, we monitored these cells using a time-lapse microscope. Of 20 control cells that entered mitosis, $60 \%(12 / 20)$ cells divided normally and reached the telophase in about 50 min (Figure 4a), 15\% (3/20) showed abnormal DNA segregation (chromosome bridge and/or unequal separation), and the remaining $25 \%$ (5/20) arrested 
a DMSO

W780

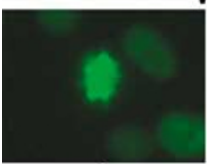

0

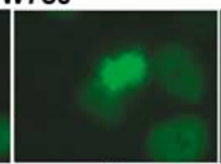

20

b Genistein

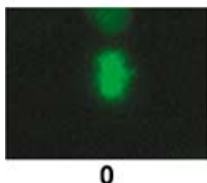

0

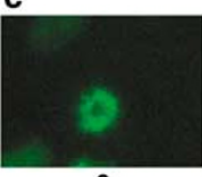

0

d

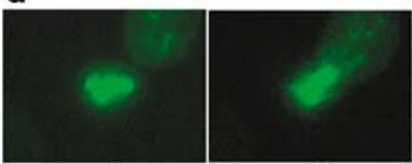

0

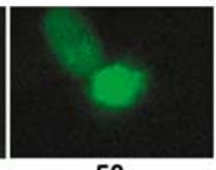

50

40

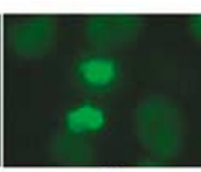

40

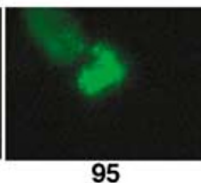

95

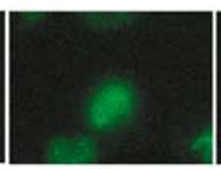

40

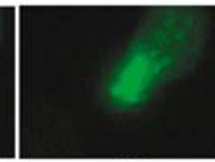

70

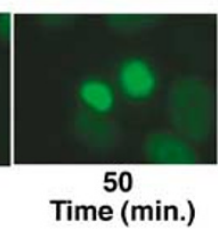

115

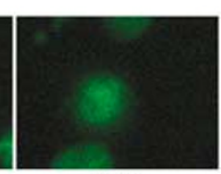

100

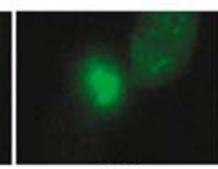

110

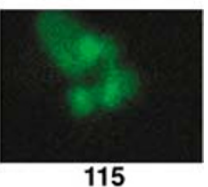

Figure 4 Abortive chromosome segregation in genistein-treated W780 cells revealed by a fluorescent time-lapse experiment. (a) Images of normal chromosome in DMSO-treated cells. (b-d) Images of abnormal chromosome in genistein-treated cells. Chromosome bridge and abnormal segregation (b). Chromosomes returned to a nuclear-like state without segregation (c). Chromosomes maintained a metaphase-like state without segregation (d)

at metaphase or returned to interphase directly (not shown). In contrast, none of the genistein-treated cells that entered mitosis $(n=12)$ displayed normal mitosis. We found that seven $(58.3 \%)$ showed abnormal DNA segregation (chromosome bridge and/or unequal separation) (Figure 4b). Three $(25 \%)$ initially arrested at metaphase and then directly returned to interphase (Figure $4 \mathrm{c}$ ). The remaining two arrested at metaphase during the 120 min of studying time (Figure 4d). Altogether, our analysis indicated that genistein treatment reduced the frequency of cells entering mitosis phase; even for the small fraction of cells that entered mitosis, they failed to complete the mitosis and returned to interphase.

Distinct chromosomal aberration found in cells treated with genistein and ICRF-193, a topoisomerase II inhibitor. To understand the reason why many of the genistein-treated cells were arrested at mitosis, we performed chromosome spread. Our analysis indicated that genistein-treated cells exhibited more extensive aneuploidy than untreated cells (Figure 5a). We also found that chromosomes from the metaphase of genistein-treated cells were frequently tangled and stick together (Figure 5b). These connections may physically prevent chromosomes at the metaphase from separation, leading to the abortive mitotic exit.

It was reported that genistein inhibits the activity of topoisomerase $\mathrm{II}{ }^{15}$ which has decatenation activity and is necessary for cells to segregate chromosome properly in the

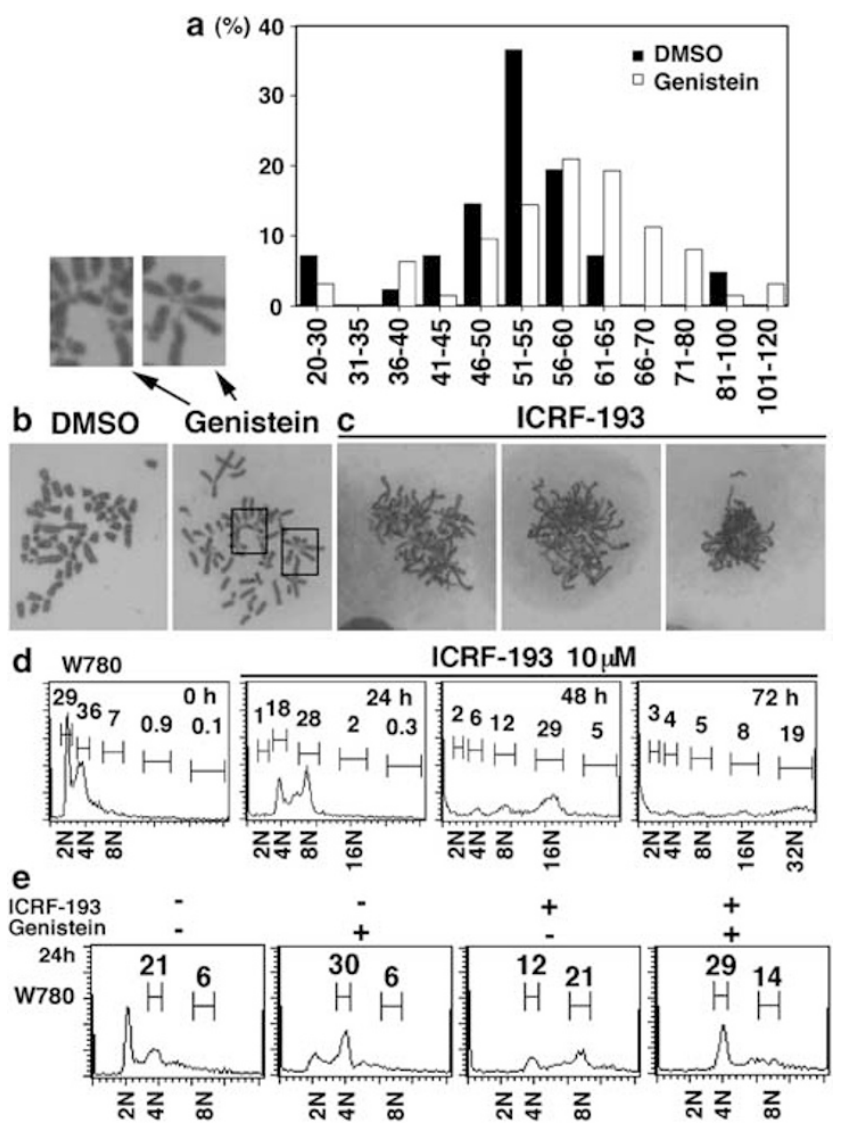

Figure 5 Chromosomal aberration and polyploid induction after genistein and/ or ICRF-193 exposure. (a) Number of chromosomes in each cell after genistein treatment for $24 \mathrm{~h}$. (b, c) Chromosome spread after $40 \mu \mathrm{M}$ genistein (b) and $10 \mu \mathrm{M}$ ICRF-193 (c) exposure. Left panel, second left panel, and the other three right panels showed representative images after DMSO, genistein, and ICRF-193 treatment, respectively. The smaller upper two panels showed enlarged images after genistein exposure. Arrowheads point to bridges that connect multiple chromosomes. (d) Flow cytometry analysis by PI staining of genistein- or ICRF-193treated cells. (e) Flow cytometry analysis by PI staining after $30 \mu \mathrm{M}$ genistein and/or $7.5 \mu \mathrm{M}$ ICRF-193 exposure

mitotic phase. ${ }^{23}$ Therefore, we hypothesized that topoisomerase II inhibitor activity in genistein could cause abnormal chromosome segregation and polyploidy. To investigate this, we treated cells with ICRF-193, which specifically inhibits topoisomerse II activity without causing DNA chain breaks. ${ }^{24}$ We found that ICRF-193 treatment induced more severe chromosome abnormalities, characterized by the severely entangled and partially condensed chromosomes (Figure 5c). Our FACS analysis revealed that, similar to genistein, ICRF-193 treatment induced the formation of polyploidy cells. However, differing from the genistein-treated cells, the polyploid cells induced by ICRF-193 displayed a continuous shift from $4 n, 8 n, 16 n$ to $32 n$ within $72 h$ through DNA endoreduplication (Figure $5 \mathrm{~d}$ ). Thus, although both genistein and ICRF-193 share a common feature in that they both induce polyploidy, genistein blocks endoreduplication 24-48 $\mathrm{h}$ after its treatment and consequently holds cells at $4 n$ and $8 n$, while ICRF-193 does not block endoreduplication, resulting in a continuous doubling of DNA content (Figure $5 \mathrm{~d}$ and 
Supplementary Table 1). These data suggest that besides the induction of polyploidy, genistein also induces other events that inhibit endoreduplication. Interestingly, our further analysis indicated that genistein could override the effect of ICRF193 and block the continuous endoreduplication caused by ICRF-193 treatment (Figure 5e), suggesting that the event induced by genistein is dominant over the endoreduplication caused by ICRF-193.

\section{Genistein exposure induces DNA damage and DNA} damage response. It was previously shown that ICRF-193 specifically inhibits topoisomerase II activity but does not cause DNA damage, while genistein inhibits topoisomerase II and induces DNA damage. ${ }^{15,24,25}$ Thus, the blocking of endoreduplication in genistein-treated cells could be due to DNA damage. To test this hypothesis, we performed immunohistochemical staining using an antibody to the phosphorylated form of $\mathrm{H} 2 \mathrm{AX}(\gamma-\mathrm{H} 2 \mathrm{AX})$, which relocates to DSBs upon DNA damage. ${ }^{26}$ Our data revealed the formation of $\gamma-\mathrm{H} 2 \mathrm{AX}$ foci in genistein-treated Brca1 mutant cells but not in untreated cells (Figures $6 a$ and b). Our staining on ICRF193-treated Brca1 mutant cells revealed a slightly increased intensity compared to background; however, it does not

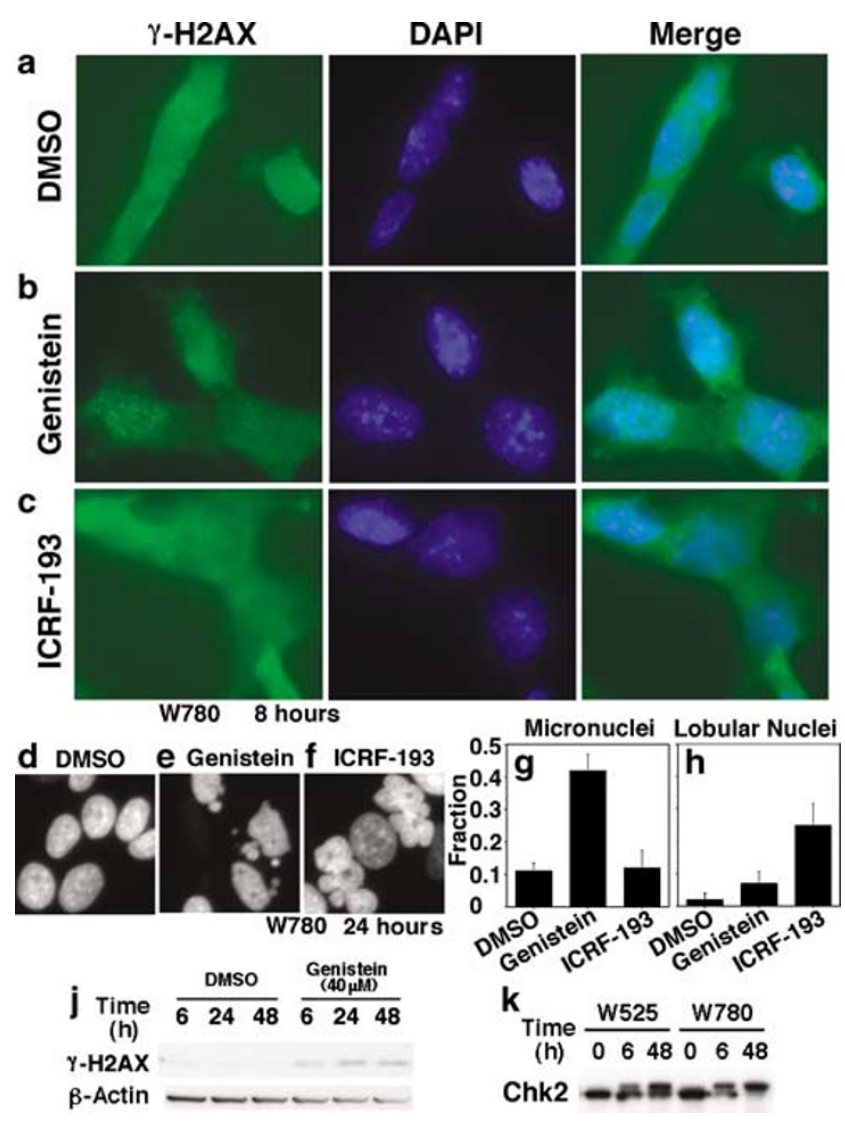

Figure 6 Genistein induced DNA damage response. (a-c) $\gamma-\mathrm{H} 2 \mathrm{AX}$ foci formation in DMSO (a)-, genistein (b)-, and ICRF-193 (c)-treated W780 cells. The cells were stained $8 \mathrm{~h}$ after the treatment. (d-f) Nuclear morphology of cells treated with DMSO (d), genistein (e), and ICRF-193 (f). (g, h) Fractions of cells with micronuclei or lobular nuclei counted and calculated in $(\mathbf{d}-\mathbf{f})$. (j, $\mathbf{k})$ Western blot analysis using antibodies against $\gamma-\mathrm{H} 2 \mathrm{AX}(\mathrm{j})$ and Chk2 (k) reach a significant level (Figure 6c). Consistent with this, we also observed micronucleus formation in the genisteintreated cells (Figure $6 \mathrm{e}$ and $\mathrm{g}$ ) but not in the DMSO- or ICRF-193-treated cells (Figure 6d,f and g). Interestingly, we found that ICRF-193 treatment primarily induced a lobular (or flower)-shaped nucleus in cells (Figure $6 f$ and $h$ ), which may reflect their active DNA endoreduplication state. Phosphorylation of H2AX in genistein-treated cells was also confirmed by Western blot analysis (Figure 6j). Thus, the significant accumulation of DNA damage upon genistein treatment could prevent cells from a continuous cycle of endoreduplication.

To understand the molecular basis for cell cycle arrest upon genistein treatment, we checked expression of Chk1 and Chk2, which are well-known mediators for the upstream kinases, ATM and ATR in DNA damage checkpoints. Our data indicated that Chk2 proteins were phosphorylated upon genistein treatment (Figure 6k). These observations provide evidence that genistein treatment induced $\gamma \mathrm{H} 2 \mathrm{AX}$ foci followed by the activation of Chk2.

\section{Discussion}

In this study, we have revealed a profound inhibitory effect of genistein on Brca1 mutant tumor cells. Our data indicate that genistein causes cell cycle arrest and mitotic catastrophe through activation of DNA damage response that inhibits growth of Brca1 mutant cancer cells. Most genistein-treated cells are arrested at the G2 phase. Although some cells entered mitosis, they exhibited chromosome abnormalities in metaphase and/or anaphase, and maintained tetraploidy due to abortive mitotic exit. A fraction of $G 2$ cells underwent endoreduplication and became polyploid (8n), which was accompanied by increased cell death. Our data also revealed a significant increase in $\gamma \mathrm{H} 2 \mathrm{AX}$ foci and activation of Chk2 upon genistein treatment. This may provide a molecular basis for cell cycle arrest, mitotic catastrophe, and increased cell death.

The relationship between consumption of soyfoods and breast cancer incidence has been studied extensively. Although most studies revealed an inhibitory effect of soyfoods consumption on breast cancer incidence, some others reported no inhibition or even a slight increase in breast cancer formation (reviewed in Magee and Rowland ${ }^{17}$ ). Similarly, discrepancy regarding genistein exposure on tumor cell growth was also reported in the studies using animal and cultured cell models. It was shown that genistein treatment reduced the incidence of breast cancer or increased the latency period in a number of animal models, including MMTV-Neu transgenic mice, ${ }^{27}$ GR mice carrying the mouse tumor virus (Mtv) gene, ${ }^{28}$ and Sprague-Dawley rats treated by DMBA. ${ }^{18}$ However, genistein exposure was found to stimulate the growth of MCF-7 cells injected into the ovariectomized nude mice model. ${ }^{29}$ The DMBA-induced breast cancer mice also showed a shortened latent period and increased cancer incidence depending on the ER $\alpha$ allele. $^{30}$ The discrepancy among different studies could be caused by multiple factors, such as different characteristics of tumor models, different dosages of genistein, and different timings of drug exposure. In this study, we showed that nearly 
all Brca1 mutant cells failed to return to $\mathrm{G} 1$ phase upon genistein treatment, while many cells driven by the oncogene ras remained in the $\mathrm{G} 1$ phase and cells driven by an activated c-neu oncogene exhibited an intermediate phenotype. Because all cells were treated under the same conditions, this different response could be attributed to the distinct intrinsic nature of these different types of cells. Furthermore, we also found that Ras and Neu cells were more resistant to genistein treatment than Brca1 mutant cells during the prolonged treatment period and the 2 days treatment followed by 3 days growth in the genistein-free medium. The extent of resistance is correlated well with the portion of cells at G1 phase. It is conceivable that cells held at the G1 phase ( $2 n$ DNA content) could reenter the cell cycle, while cells held at the G2 phase ( $4 n$ or higher DNA content) fail to proliferate even after removal of the drug.

A significant feature of genistein exposure is induction of the polyploid population of cells. It is possible that genistein treatment activates signaling responsible for cell cycle checkpoint activation that blocks the cell cycle progression and holds cells at G2 phase. We observed tremendous chromosome aberration, mainly chromosome bridge formation. Therefore, the mechanism of polyploidy induction may be that the mitotic fraction $(4 n)$, which gradually escapes from the G2/M checkpoint after genistein exposure, could not separate chromosomes probably due to bridging chromosome formation. These cells could not finish mitosis and maintain a tetraploid state. Through endoreduplication, some of these cells doubled their DNA content leading to the formation of $8 n$ cells.

In addition, it was shown that BRCA1 interacts and colocalizes with topoisomerase $\|-\alpha$ in S-phase cells and may be involved in the decatenation checkpoint pathway. ${ }^{31,32}$ It is demonstrated that BRCA1 is required for ubiquitination of topoisomerase II-alpha, and topoisomerase II-alpha ubiquitination correlates with higher DNA decatenation activity. BRCA1 deficiency, consequently, results in defective DNA decatenation. Our analysis indicated that about $40 \%$ Brca1 mutant cells failed to separate their chromosomes properly prior to genistein treatment. This observation suggests that defective decatenation partially contributes to polyploidy formation or Brca1 deficiency does not cause the complete loss of the decantation checkpoint. Nonetheless, we showed that all the cells showed chromosome abnormalities upon genistein treatment. Because genistein also inhibits the activity of topoisomerase II (reviewed in Polkowski et al. ${ }^{33}$ ), we have compared the effects of genistein and ICRF-193, which inhibits topoisomerase II catalytic activity. Our data reveal a couple of interesting findings. First, both ICRF-193 and genistein can induce polyploidy; however, the former causes continuous polyploidization while the later stopped at $4 n$ and $8 n$. Second, despite the fact that ICRF-193 is more potent in inducing polyploidization, its effect can be overridden by genistein. Our interpretation is that genistein exposure can induce polyploidization because of its ability to inhibit topoisomerase II, but it also activates DNA damage response that eventually blocks endoreduplication even in the presence of ICRF-193.

It has been reported that genistein exposure can induce oxidative DNA damage, while ICRF-193 does not have this ability. ${ }^{24,25}$ Our analysis revealed by the formation of the phosphorylated form of $\mathrm{H} 2 \mathrm{AX}(\gamma \mathrm{H} 2 \mathrm{AX})$ foci in the genisteintreated cells but not in the ICRF-193-treated cells confirmed this notion. A number of recent investigations indicate that DNA damage response is characterized by the formation of $\gamma \mathrm{H} 2 \mathrm{AX}$ foci followed by the activation of ATM-Chk2-p53 signaling. ${ }^{34,35}$ The DNA damage response serves as a barrier to prevent cell proliferation and eliminate cells with unrepairable DNA damage due to p53-dependent cell cycle arrest and apoptosis. Because all the Brca1 mutant cells used in this study are p53 deficient, ${ }^{21}$ the cell cycle arrest and apoptosis caused by genistein treatment are p53 independent. The identity of the factors that are involved in these processes is currently unclear, as ATM and Chk2 can phosphorylate many proteins besides p53. ${ }^{36}$ This is an interesting topic and will be addressed in a future study.

Cancer prevention by natural foods, such as soy and soybean, may have a great potential for preventing mammary carcinogenesis. As regular foods, they are accessible for a vast majority of patients. Our finding that genistein can kill p53 and Brca1 double mutant breast cancer cells is significant as over $90 \%$ of human BRCA1 mutation-associated breast cancers do not contain functional p53. ${ }^{37}$ Because of the estrogen-like effects of genistein, there is concern over a possible detrimental effect of soy in breast cancer patients. Indeed, it was shown that low concentrations of genistein (i.e. $<10 \mu \mathrm{M})$ could function like estrogen to stimulate cell proliferation. ${ }^{19}$ However, the majority of BRCA1 tumors are $\mathrm{ER} \alpha$ negative ${ }^{38-41}$ suggesting that it should not be a concern in BRCA1 breast cancer. It is also questionable that a DNAdamaging agent, such as genistein, could be a candidate for chemopreventive reagent for BRCA1 mutation carriers. One explanation is that normal somatic cells still have normal genetic information, for example, one normal allele of BRCA1. Such cells have normal cell cycle checkpoint and DNA repair ability so that the cells can avoid or minimize the harmful effects of genistein. BRCA1 mutant cells are defective in repairing their DNA DSBs, which make the mutant cells more sensitive to genistein. Given the high risk of BRCA1 mutation carriers for the development of breast cancer, these findings suggest that genistein should serve as a useful drug in the chemoprevention and/or therapeutic treatment of BRCA1associated breast cancer.

\section{Materials and Methods}

Cell lines and treatment. Four mouse mammary tumor cell lines were used: W525, W780 were established from mammary tumors of $\mathrm{Brca} 1^{\mathrm{Ko} / \mathrm{CO}}$;WAPCre; $53^{+/-}$mice; ras and neu cell lines were established from mammary tumors developed in MMTV-ras and MMTV-neu, respectively. ${ }^{21}$ For MTT [3-(4,5dimethylthiazol-2-yl)-2,5-diphenyl tetrazolium bromide] assay, we plated 1$2 \times 10^{4}$ cells per one well of a 24-well plate. Each point is in triplicate. After $24 \mathrm{~h}$, we changed the medium with genistein dissolved in DMSO with varying concentrations. At different time points, we removed the medium and added $0.5 \mathrm{ml}$ of $0.1 \%$ MTT solution dissolved by PBS in each well. After $30 \mathrm{~min}$ in a $37^{\circ} \mathrm{C}$ $\mathrm{CO}_{2}$ incubator, we removed MTT solution and added $0.4 \mathrm{ml}$ of 2-propanol. After shaking for $30 \mathrm{~min}$, we measured OD560 using a plate reader.

FACS analysis. We plated $2.5 \times 10^{5}-2 \times 10^{6}$ cells into a $100 \mathrm{~mm}$ dish. At $24 \mathrm{~h}$ after plating, cells were treated with genistein or DMSO as a control. We labeled cells by adding a 1000 -fold diluted BrdU reagent (HE Healthcare) into medium $30 \mathrm{~min}$ before harvesting. After trypsinization, cells were fixed by $70 \%$ ethanol, and treated with $2 \mathrm{~N} \mathrm{HCl}$ and $0.5 \%$ Triton $\mathrm{X}-100$. Cells were then stained with an 
anti-BrdU FITC (BD Biosciences) or anti-BrdU Pure (BD Biosciences) antibody as a first antibody followed by using an Alexa Fluor 488 goat anti-mouse $\lg G(\mathrm{H}+\mathrm{L})$ (Molecular Probes) antibody and stained with PI for fluorescent labeling. Cells were analyzed by FACS caliber using the cell quest as a software (Beckton Dickinson). To analyze mitotic fraction, we used an anti-phospho-histone H3 (Ser10) (Upstate) antibody followed by an Alexa Fluor 488 goat anti-rabbit $\lg G(\mathrm{H}+\mathrm{L})$ (Molecular Probes) as a second antibody with PI.

Allograft experiments. At 1 week before inoculating cells into female nude mice (Jackson), we fed the mice with control diet (AIN-76A) and genisteincontaining diet (AIN-76A plus genistein at a concentration of $0.75 \mathrm{mg} / \mathrm{g}$; Research Diets, Inc.). Mutant mammary tumor cells $\left(1 \times 10^{6}\right.$ cells/injection) were inoculated subcutaneously on the lateral body wall of nude mice (two sites/mouse and five mice/group). We calculated tumor volume ( $V$ by the formula $V=a b^{2} / 2$, where a and $b$ are tumor length and width, respectively.

Cell cycle analysis by immunostaining. We plated $1 \times 10^{4}$ cells into a four-well chamber slide (Beckton Dickinson), which was treated with $1 \mu \mathrm{g} / \mathrm{ml}$ poly L-lysin in $\mathrm{H}_{2} \mathrm{O}$ for $30 \mathrm{~min}$. After 1 day, cells were treated with genistein or vehicle (DMSO) for varying times before they were fixed with $100 \%$ methanol for $5 \mathrm{~min}$ at $\mathrm{RT}$ on the slides. Fixed cells were washed three times with PBS and blocked with $3 \%$ BSA in PBS for 10 min at RT. They were incubated with monoclonal anti-alphatubulin antibody (Sigma) $(1: 1000)$ and polyclonal antibody against pericentrin (PRB-432C, COVANCE) $(1: 300)$ with $3 \%$ BSA in PBS overnight. The cells were washed three times with $3 \%$ BSA in PBS and incubated with Alexa Fluor 546 goat anti-mouse $\lg G(H+L)$ (Molecular Probes) (1: 1000), Alexa Fluor 488 goat antirabbit lgG $(\mathrm{H}+\mathrm{L})$ (Molecular Probes) (1: 1000), and DAPI $100 \mathrm{ng} / \mathrm{ml}$ in $3 \% \mathrm{BSA}$ in PBS for $1 \mathrm{~h}$. The cells were washed three times with PBS, and a cover glass was placed on the chamber glass and sealed with nail polish. We captured fluorescent images by a CCD camera connected to a Leica DMR fluorescent microscope with MagnaFire 2.0 application.

Time lapse. Cells carrying a stably expressed histone H2B-GFP expression vector were grown on a small dish designed for time lapse (Delta T Dish, $0.17 \mathrm{~mm}$ in diameter, Bioptechs, Inc.) for 1 day in $37^{\circ} \mathrm{C} \mathrm{CO}_{2}$ incubator. At 1 day after treating with $40 \mu \mathrm{M}$ genistein, the cells were transferred onto an incubating stage of an Olympus IX81 inverted microscope with thermometer and thermostat controlling system (Delta T4 Culture Dish Controller, Bioptechs, Inc.). Fluorescent images using a $\times 20$ objective lens were taken every 5 min for $2 \mathrm{~h}$ with IPLab as software.

Western blot analysis. Western blot analysis was performed using standard procedures for whole-cell extracts from cell lines. Antibodies used include Chk2 (Transduction Laboratories), $\gamma-\mathrm{H} 2 \mathrm{AX}$ (Upstate), and $\beta$-actin (Sigma). We used antirabbit Ig, horseradish peroxidase (GH Healthcare), or anti-mouse lg-POD (Roche) as a second antibody. We used chemiluminescent method (GE healthcare) and autoradiography to obtain images.

Acknowledgements. We thank Jesoph De Soto for a critical reading of this manuscript and all members of Deng's laboratory for technical assistance and advice. This research was supported by the Intramural Research Program of the National Institute of Diabetes, Digestive and Kidney Diseases, National Institutes of Health, USA.

1. Zhang J, Powell SN. The role of the BRCA1 tumor suppressor in DNA double-strand break repair. Mol Cancer Res 2005; 3: 531-539.

2. Alberg AJ, Lam AP, Helzlsouer KJ. Epidemiology, prevention, and early detection of breast cancer. Curr Opin Oncol 1999; 11: 435-441.

3. Brody LC, Biesecker BB. Breast cancer susceptibility genes. BRCA1 and BRCA2. Medicine (Baltimore) 1998; 77: 208-226

4. Eccles DM, Pichert G. Familial non-BRCA1/BRCA2-associated breast cancer. Lancet Oncol 2005; 6: 705-711.

5. Miki Y, Swensen J, Shattuck-Eidens D, Futreal PA, Harshman K, Tavtigian S et al. A strong candidate for the breast and ovarian cancer susceptibility gene BRCA1. Science 1994; 266: $66-71$

6. Easton DF, Ford D, Bishop DT. Breast and ovarian cancer incidence in BRCA1-mutation carriers. Breast Cancer Linkage Consortium. Am J Hum Genet 1995; 56: 265-271.

7. Struewing JP, Hartge P, Wacholder S, Baker SM, Berlin M, McAdams M et al. The risk of cancer associated with specific mutations of BRCA1 and BRCA2 among Ashkenazi Jews. N Engl J Med 1997; 336: 1401-1408.
8. Ford D, Easton DF, Stratton M, Narod S, Goldgar D, Devilee P et al. Genetic heterogeneity and penetrance analysis of the BRCA1 and BRCA2 genes in breast cancer families. The Breast Cancer Linkage Consortium. Am J Hum Genet 1998; 62: 676-689.

9. Ziegler RG, Hoover RN, Pike MC, Hildesheim A, Nomura AM, West DW et al. Migration patterns and breast cancer risk in Asian-American women. J Natl Cancer Inst 1993; 85 $1819-1827$.

10. Lee HP, Gourley L, Duffy SW, Esteve J, Lee J, Day NE. Dietary effects on breast-cancer risk in Singapore. Lancet 1991; 337: 1197-1200.

11. Yamamoto S, Sobue T, Kobayashi M, Sasaki S, Tsugane S. Soy, isoflavones, and breast cancer risk in Japan. J Natl Cancer Inst 2003; 95: 906-913.

12. Skibola CF, Smith MT. Potential health impacts of excessive flavonoid intake. Free Radic Biol Med 2000; 29: 375-383.

13. Cappelletti V, Fioravanti L, Miodini P, Di Fronzo G. Genistein blocks breast cancer cells in the G(2)M phase of the cell cycle. J Cell Biochem 2000; 79: 594-600.

14. Hewitt AL, Singletary KW. Soy extract inhibits mammary adenocarcinoma growth in a syngeneic mouse model. Cancer Lett 2003; 192: 133-143.

15. Markovits J, Linassier C, Fosse P, Couprie J, Pierre J, Jacquemin-Sablon A et al. Inhibitory effects of the tyrosine kinase inhibitor genistein on mammalian DNA topoisomerase II. Cancer Res 1989; 49: 5111-5117.

16. Li Y, Bhuiyan M, Sarkar FH. Induction of apoptosis and inhibition of c-erbB-2 in MDA MB-435 cells by genistein. Int J Oncol 1999; 15: 525-533.

17. Magee PJ, Rowland IR. Phyto-oestrogens, their mechanism of action: current evidence for a role in breast and prostate cancer. Br J Nutr 2004; 91: 513-531.

18. Lamartiniere CA, Moore JB, Brown NM, Thompson R, Hardin MJ, Barnes S. Genistein suppresses mammary cancer in rats. Carcinogenesis 1995; 16: 2833-2840.

19. Hsieh CY, Santell RC, Haslam SZ, Helferich WG. Estrogenic effects of genistein on the growth of estrogen receptor-positive human breast cancer (MCF-7) cells in vitro and in vivo. Cancer Res 1998; 58: 3833-3838.

20. Allred CD, Allred KF, Ju YH, Virant SM, Helferich WG. Soy diets containing varying amounts of genistein stimulate growth of estrogen-dependent (MCF-7) tumors in a dosedependent manner. Cancer Res 2001; 61: 5045-5050.

21. Brodie SG, Xu X, Qiao W, Li WM, Cao L, Deng CX. Multiple genetic changes are associated with mammary tumorigenesis in Brca1 conditional knockout mice. Oncogene 2001; 20: 7514-7523

22. Wang $\mathrm{RH}, \mathrm{Yu} \mathrm{H}$, Deng $\mathrm{CX}$. A requirement for breast-cancer-associated gene 1 (BRCA1) in the spindle checkpoint. Proc Natl Acad Sci USA 2004; 101: 17108-17113.

23. Ishida R, Sato M, Narita T, Utsumi KR, Nishimoto T, Morita T et al. Inhibition of DNA topoisomerase II by ICRF-193 induces polyploidization by uncoupling chromosome dynamics from other cell cycle events. J Cell Biol 1994; 126: 1341-1351.

24. Skoufias DA, Lacroix FB, Andreassen PR, Wilson L, Margolis RL. Inhibition of DNA decatenation, but not DNA damage, arrests cells at metaphase. Mol Cell 2004; 15: $977-990$

25. Murata M, Midorikawa K, Koh M, Umezawa K, Kawanishi S. Genistein and daidzein induce cell proliferation and their metabolites cause oxidative DNA damage in relation to isoflavone-induced cancer of estrogen-sensitive organs. Biochemistry 2004; 43 2569-2577.

26. Paull TT, Rogakou EP, Yamazaki V, Kirchgessner CU, Gellert M, Bonner WM. A critical role for histone $\mathrm{H} 2 \mathrm{AX}$ in recruitment of repair factors to nuclear foci after DNA damage. Curr Biol 2000; 10: 886-895.

27. Jin Z, MacDonald RS. Soy isoflavones increase latency of spontaneous mammary tumors in mice. J Nutr 2002; 132: 3186-3190.

28. Mizunuma $\mathrm{H}$. Effect of combination treatment with estrogen and vitamin D3 on postmenopausal boneless. Clin Calcium 2002; 12: 944-948.

29. Ju YH, Allred CD, Allred KF, Karko KL, Doerge DR, Helferich WG. Physiological concentrations of dietary genistein dose-dependently stimulate growth of estrogendependent human breast cancer (MCF-7) tumors implanted in athymic nude mice. J Nutr 2001; 131: 2957-2962.

30. Youssoufian H. Fanconi anemia and breast cancer: what's the connection? Nat Genet 2001; 27: 352-353.

31. Lou Z, Minter-Dykhouse K, Chen J. BRCA1 participates in DNA decatenation. Nat Struct Mol Biol 2005; 12: 589-593.

32. Deming PB, Cistulli CA, Zhao H, Graves PR, Piwnica-Worms H, Paules RS et al. The human decatenation checkpoint. Proc Natl Acad Sci USA 2001; 98 12044-12049.

33. Polkowski K, Popiolkiewicz J, Krzeczynski P, Ramza J, Pucko W, Zegrocka-Stendel et al. Cytostatic and cytotoxic activity of synthetic genistein glycosides against human cancer cell lines. Cancer Lett 2004; 203: 59-69.

34. Bartkova J, Horejsi Z, Koed K, Kramer A, Tort F, Zieger $\mathrm{K}$ et al. DNA damage response as a candidate anti-cancer barrier in early human tumorigenesis. Nature 2005 434: 864-870.

35. Gorgoulis VG, Vassiliou LV, Karakaidos P, Zacharatos P, Kotsinas A, Liloglou T et al. Activation of the DNA damage checkpoint and genomic instability in human precancerous lesions. Nature 2005; 434: 907-913.

36. Pommier Y, Sordet O, Rao VA, Zhang H, Kohn KW. Targeting chk2 kinase: molecular interaction maps and therapeutic rationale. Curr Pharm Des 2005; 11: 2855-2872.

37. Schuyer M, Berns EM. Is TP53 dysfunction required for BRCA1-associated carcinogenesis? Mol Cell Endocrinol 1999; 155: 143-152. 
38. Eisinger $F$, Jacquemier J, Nogues C, Birnbaum D, Sobol H. Steroid receptors in hereditary breast carcinomas associated with BRCA1 or BRCA2 mutations or unknown susceptibility genes. Cancer 1999; 85: 2291-2295.

39. Loman N, Johannsson O, Bendahl PO, Borg A, Ferno M, Olsson H. Steroid receptors in hereditary breast carcinomas associated with BRCA1 or BRCA2 mutations or unknown susceptibility genes. Cancer 1998; 83: 310-319.
40. Karp SE, Tonin PN, Begin LR, Martinez JJ, Zhang JC, Pollak MN et al. Influence of BRCA1 mutations on nuclear grade and estrogen receptor status of breast carcinoma in Ashkenazi Jewish women. Cancer 1997; 80: 435-441.

41. Johannsson OT, Idvall I, Anderson C, Borg A, Barkardottir RB, Egilsson V et al. Tumour biological features of BRCA1-induced breast and ovarian cancer. Eur J Cancer 1997; 33: 362-371.

Supplementary Information accompanies the paper on Cell Death and Differentiation website (http://www.nature.com/cdd) 